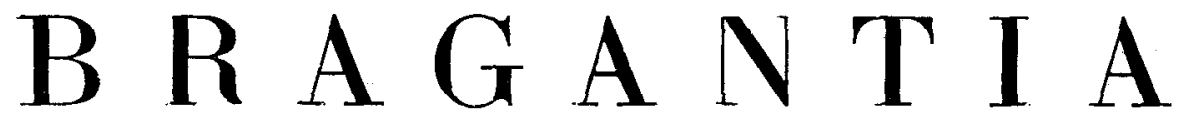

Boletim Científico do Instituto Agronômico do Estado de S. Paulo

Vol. 26

Campinas, setembro de 1967

N. ${ }^{\circ} 31$

\title{
ABSORÇÃO DE NUTRIENTES PELA PLANTA DE AMENDOIM EM CULTURA DE PRIMAVERA ${ }^{(1)}$
}

Fernando A. Soares Coelho, engenheiro-agrônomo, Seção de Fertilidade do Solo, e ROMEU DE TELLA, engenheiro-agrônomo, Seção de Oleaginosas, Instituto Agronômico

\section{SINOPSE}

É apresentado estudo relativo à acumulação de matéria sêca, concentração $P$ absorção de nutrientes em plantas de amendoim, em latossolo vermelho escuro, adubado e sem adubação. Em amostras de plantas colhidas semanalmente foram determinados os elementos: N, P, K, Ca, $\mathrm{Mg}$ e $\mathrm{S}$.

A adubação trouxe aumento de $85 \%$ no pêso sêco dos frutos e $53 \%$ no da planta. Com exceção do cálcio e do magnésio, os teores dos demais elementos foram mais elevados nas plantas adubadas.

Cêrca de $80 \%$ do total de matéria sêca e de nutrientes nas plantas adubadas foram acumulados no período entre início da frutificação e início da maturação dos frutos.

Nas plantas não adubadas essa acumulação representa cêrca de $60 \%$. Êsses resultados evidenciam o período em que as plantas devem encontrar maior disponibilidade de nutrientes no solo.

\section{1 - INTRODUÇÃO}

O estudo da acumulação de nutrientes e de matéria sêca através da análise química de plantas cultivadas em condições de campo, e feita em diferentes épocas do ciclo vegetativo, fornece indicações úteis quanto à nutrição das plantas, evidenciando a importância relativa dos nutrientes e sua dinâmica dentro da planta. Indicam a quantidade total de nutrientes extraidos pelas

(1) Recebido para publicaçáo em 1 de junho de 1967. 
plantas e os periodos em que elas absorvem os elementos nutritivos em maior proporção, revelando as épocas mais adequadas para utilização das práticas de adubação.

O presente trabalho visa o estudo da absorção de $\mathbf{N}, \mathrm{P}, \mathrm{K}$, $\mathrm{Ca}, \mathrm{Mg}$ e $\mathrm{S}$ e acumulação de matéria sêca pelas plantas de amendoim, variedade Tatu, nas condições de solos e clima do experimento.

\section{2 - MATERIAL E MÉTODO}

Em solo latossolo vermelho escuro foram semeadas duas áreas com amendoim, variedade Tatu, no espaçamento de $60 \mathrm{~cm} \times 10 \mathrm{~cm}$, uma sem adubação e outra com adubação, incluindo micronutrientes, destinadas ao estudo da absorção de nutrientes pelo amendoim. Cada parcela era constituída de 10 linhas de $24 \mathrm{~m}$ de comprimento, com uma planta por cova após o desbaste. No tratamento adubado, além de NPK, foram incluídos micronutrientes e sulfato de cálcio, nas seguintes doses, em quilogramas por hectare: salitre do Chile, 390 ; superfosfato simples, 600 ; cloreto de potássio, 135; sulfato de cálcio, 500; sulfato de zinco, 20; sulfato de cobre, 20 ; borax, 3 ; molibdato de amônio 0,115 . O salitre do Chile foi aplicado em cobertura, cêrca de 30 dias de idade das plantas, e os demais na linha, por ocasião do plantio. cultura.

Os tratos culturais foram os mesmos recomendados para a

A análise química do solo, efetuada pela Seção de Fertilidade do Solo, revelou os seguintes resultados:

$\mathrm{pH} \ldots \ldots \ldots \ldots \ldots \ldots \ldots \ldots \ldots \ldots \ldots \ldots, 5,15$

Nitrogênio $(\mathrm{N}), \mathrm{g} / 100 \mathrm{~g}$ de solo $\ldots \ldots \ldots \ldots, 0,12$

$\mathrm{Ca}++$ trocável, e.mg/100g de solo ..... 0,30

\begin{tabular}{|c|c|c|c|c|c|}
\hline $\mathbf{M g}++$ & $"$ & $"$ & $"$ & $"$ & \\
\hline $\mathbf{K}+$ & $"$ & $"$ & $"$ & $"$ & $\ldots$ \\
\hline $\mathrm{Al}+++$ & " & $"$ & $"$ & $"$ & \\
\hline $\mathrm{H}^{+}$ & $"$ & " & $"$ & $"$ & \\
\hline
\end{tabular}

$\mathrm{PO}_{4}^{--}\left(^{2}\right)$ e. $\mathrm{mg} / 100 \mathrm{~g}$ de solo $\ldots \ldots \ldots \ldots, 0,16$

(2) Fosfato solúvel em $\mathrm{H}_{2} \mathrm{SO}_{4} 0,05 \mathrm{~N}$ 
Os resultados da análise revelam que o solo em que se efetuou o plantio possui baixo teor em todos os nutrientes, com exceção do nitrogênio, que é médio. A acidez, representada pelo indice $\mathrm{pH}$, é média.

Semeou-se o amendoim em 17 de outubro de 1962, e a colheita foi feita em 6 de fevereiro de 1963. Os dados pluviométricos, fornecidos pela Seção de Climatologia Agrícola, dêste Instituto, acham-se reunidos no quadro 1.

QUadro 1. - Dados pluviométricos, no período de outubro de 1962 a fevereiro de 1963

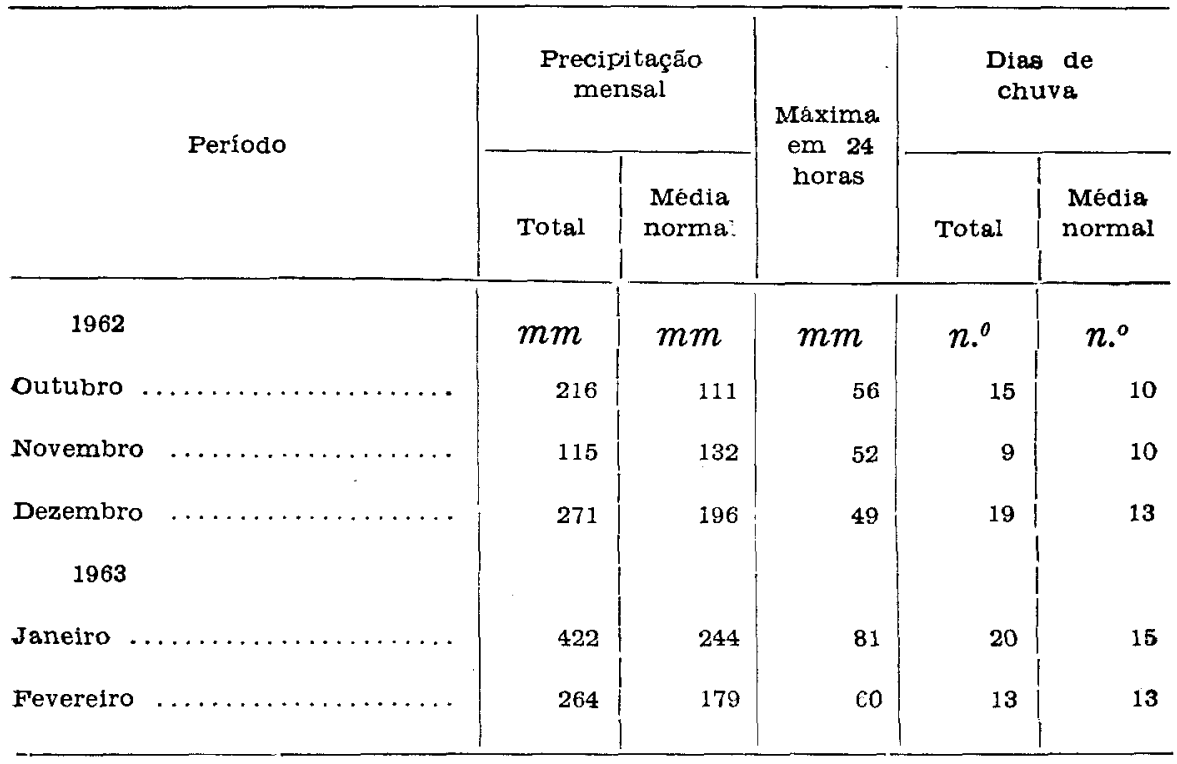

A amostragem foi feita arrancando-se 20 plantas, por vez, de cada tratamento, a primeira realizada duas semanas após a germinação, e as demais semanalmente, até a colheita.

O preparo das amostras e suas análises químicas foram efetuadas de acôrdo com as técnicas já descritas $(8,9,4)$.

\section{3 - RESULTADOS OBTIDOS}

\section{1 - ACUMULAÇĀO DE MATÉRIA SÊCA}

A figura 1 mostra que houve um aumento de material sêco da planta total até 13 semanas de idade, quando iniciou um pe- 
ríodo de queda de fôlhas provocada pela doença "mancha das fôlhas", causada pelo fungo Cercospora sp., sendo que nas plantas adubadas observou-se diminuiçāo de pêso sêco total, a partir dêsse momento. Nas que não receberam adubação não houve êsse decréscimo, devido à uniformidade de acumulação de matéria sêca pelas plantas durante todo o ciclo vegetativo.

O comportamento da parte vegetativa das plantas com relaçāo à acumulação de matéria sêca foi idêntico ao ocorrido com a planta total no tratamento adubado.

O período mais ativo de acumulação de matéria sêca foi entre 0 início da frutificação e o da queda das fôlhas. Pràticamente, até o início da frutificação nāo houve diferença entre o pêso sêco das plantas, o que evidencia que o período de mais intensa acumulação de matéria sêca é após êsse estádio, quando as plantas devem encontrar maior disponibilidade de nutrientes no solo.

À época da colheita, observou-se que a adubação motivou um aumento de $85 \%$ no pêso sêco dos frutos e de $53 \%$ no da planta total.

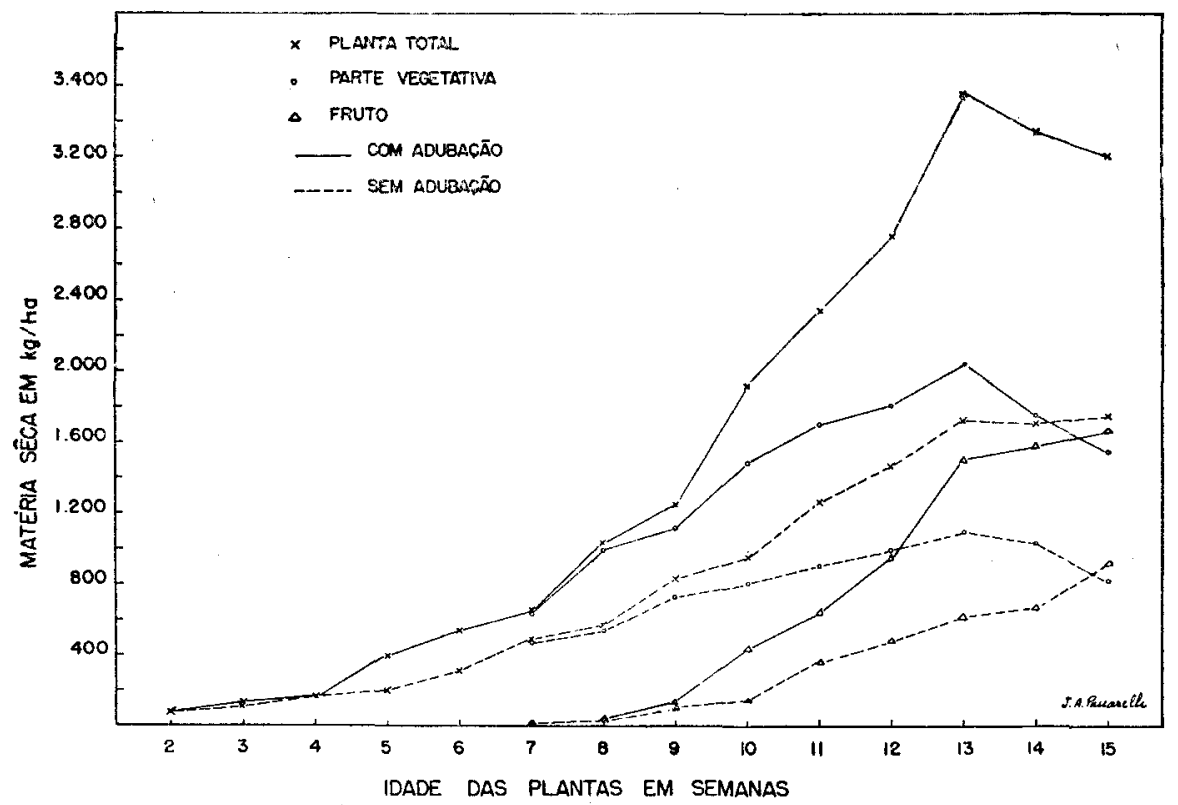

Figura 1. - Curvas de acumulação de matéria sêca pelas plantas de amendoim e partes da planta nos tratamentos sem e com adubaçá 
FERNANDO A. SOARES COELHO \& ROMEU DE TELLA

\section{2 - VARIAÇÃO NA CONCENTRAÇÃO DE NUTRIENTES}

Os gráficos das figuras 2 e 3 mostram a composição química das partes da planta, em diferentes fases do ciclo vegetativo.

Os teores de nitrogênio e fósforo na haste, em ambos os tratamentos, decresceram com a idade das plantas. Os teores de potássio, nessa mesma parte, sofreram variaçōes com o desenvolvimento da planta, não apresentando tendência definida de aumento ou diminuição. A concentração de cálcio na haste das plantas, em ambos os tratamentos, e a de enxofre nas plantas não adubadas, aumentou com o desenvolvimento da planta até a colheita, enquanto que nas plantas adubadas decresceu, aumentando no fim do ciclo. A concentração de magnésio decresceu até o inicio da frutificação e de florescimento, para em seguida experimentar um aumento até o fim do ciclo, respectivamente, nas plantas com e sem adubação.

A concentração dos elementos nutritivos nas fôlhas e raízes apresenta comportamento semelhante ao da concentração na haste.

$\mathrm{Na}$ casca do fruto, os teores de nitrogênio, fósforo, potássio e magnésio, nas plantas de ambos os tratamentos, e de enxôfre, nas plantas adubadas, decresceram durante o ciclo vegetativo, sendo que os de enxôfre nas plantas não adubadas aumentaram no período inicial de frutificação, decrescendo em seguida até a colheita. Quanto ao cálcio, houve um ligeiro aumento no seu teor, com o desenvolvimento dos frutos.

$\mathrm{Na}$ semente, a concentração dos elementos nutritivos foi a seguinte: o nitrogênio aumentou em ambos os tratamentos durante o desenvolvimento, acontecendo o contrário com o potássio; o fósforo, diminuiu inicialmente para aumentar durante a maturaçāo do fruto, enquanto que a do enxôfre teve comportamento inverso; cálcio e magnésio permaneceram pràticamente constantes. As sementes apresentaram teores mais elevados de nitrogênio e fósforo e mais baixos de cálcio e magnésio.

Com exceção do cálcio e magnésio, que apresentaram teores mais elevados nas plantas não adubadas, a adubação motivou um aumento nos teores de todos os elementos. Os maiores acréscimos foram apresentados pelo enxôfre, fósforo e potássio. 


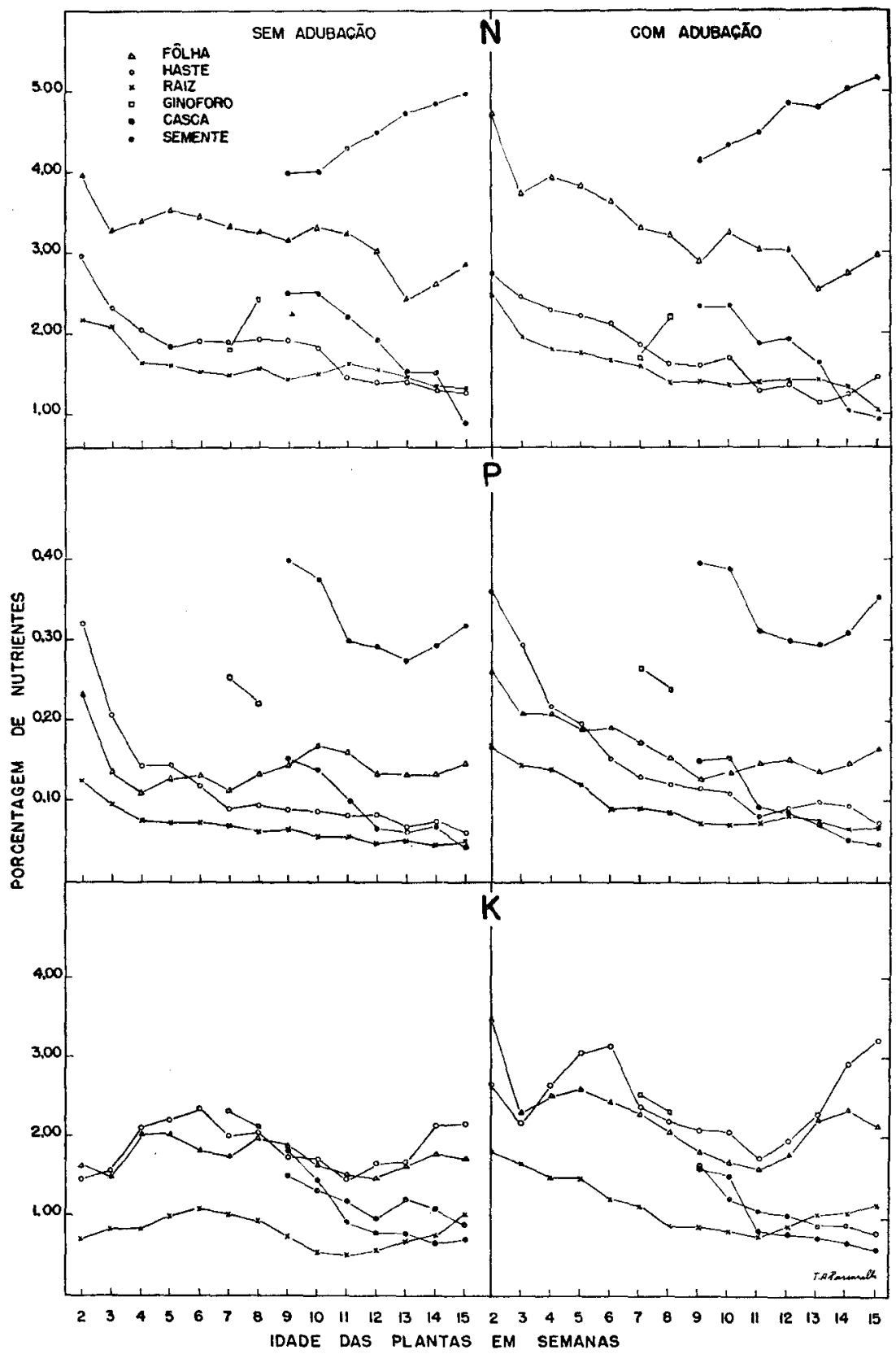

Figura 2. - Concentração de nitrogênio, fósforo e potássio nas diversas partes da planta de amendoim, nos tratamentos sem e com adubaçáo, de acôrdo com a idade das plantas. 
FERNANDO A. SOARES COELHO \& ROMEU DE TELLA

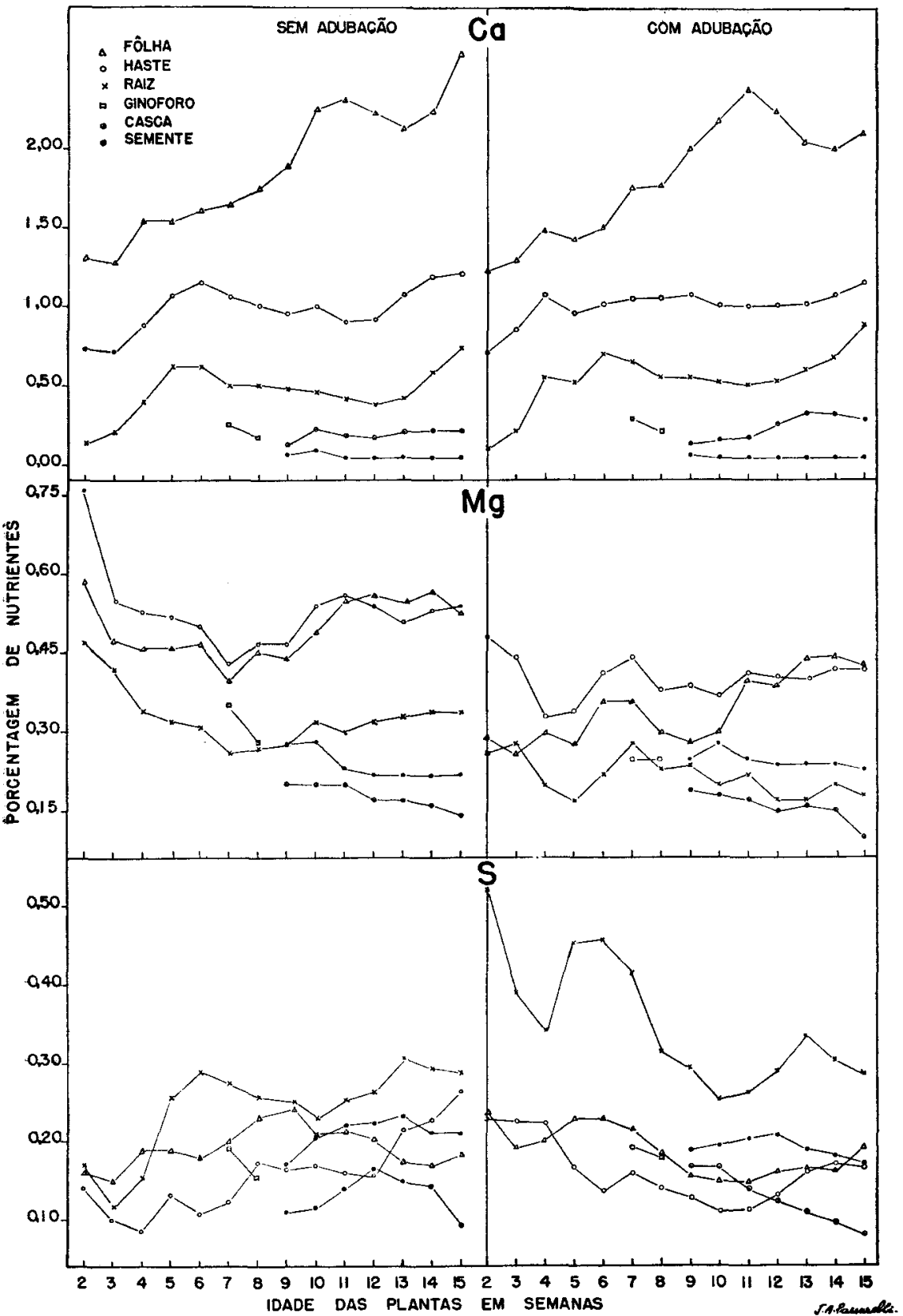

Figura 3. - Concentração đe cálcio, magnésio e enxôfre nas diversas partes da planta de amendoim, nos tratamentos sem e com adubação, de acôrdo com a idade das plantas. 


\section{3 - ABSORÇÃO DE NUTRIENTES \\ 3.3.1 - QUANTIDADE E DISTRIBUIÇÃO}

As quantidades de nutrientes extraídas e sua distribuição nas plantas são apresentadas no quadro 2.

Os elementos absorvidos em maiores quantidades, em ordem descrescente foram: nitrogênio, potássio e cálcio. Cêrca de $68 \%$ do nitrogênio e $73 \%$ do fósforo extraidos pelas plantas acham-se encerrados nos frutos, enquanto que cêrca de $93 \%$ do cálcio encontra-se na parte vegetativa. Para os demais elementos a parte vegetativa encerra a maior quantidade extraída.

Observou-se uma transmigração acentuada de nitrogênio e fósforo de tôdas as partes da planta para a semente. $O$ enxôfre migrou da raíz, também, para a semente. Para os demais elementos observou-se muito pouca transmigração, e, principalmente, da casca para a semente.

\subsection{2 — INTENSIDADE DE ABSORÇÃO}

A atividade de absorção de nutrientes, em gramas por hectare por dia, em intervalo de duas semanas, até a época da colheita, é mostrada na figura 4. Nas plantas adubadas, o periodo.

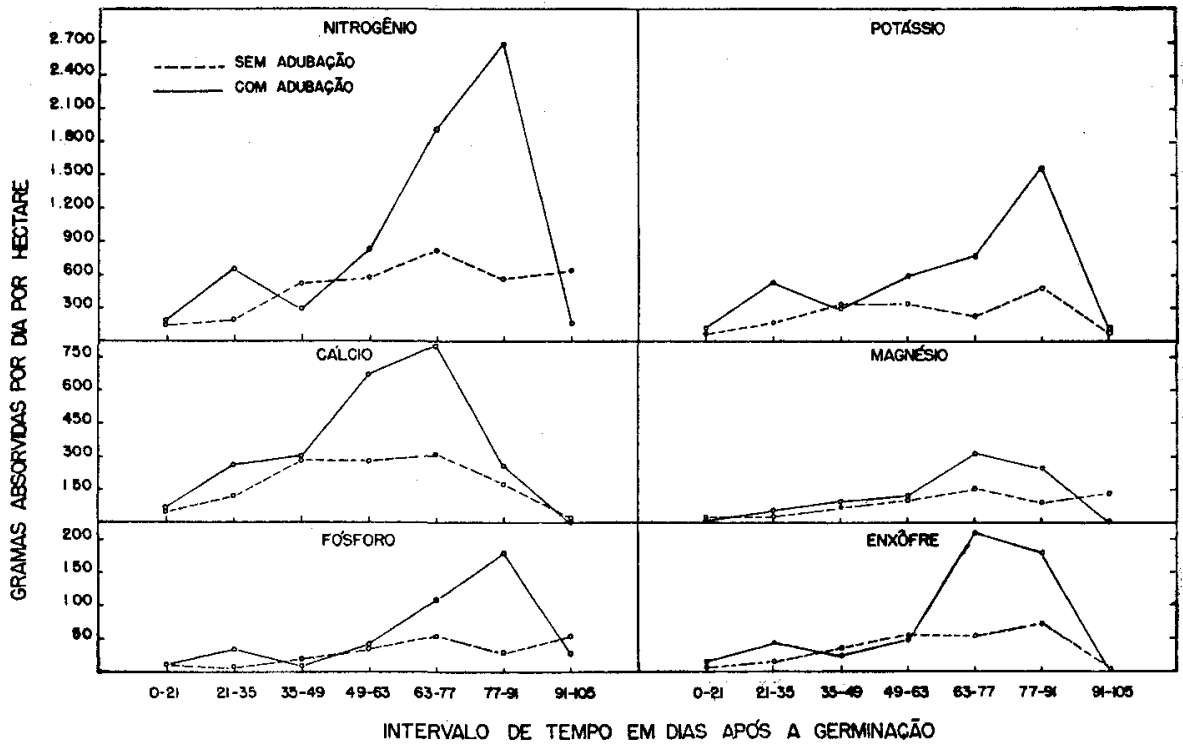

Figura 4. - Intensidade de absorçáo de nutrientes pelas plantas de amendoim. de acôrdo com o período de desenvolvimento, nos tratamentos sem e com ađubação. 
FERNANDO A. SOARES COELHO \& ROMEU DE TELLA

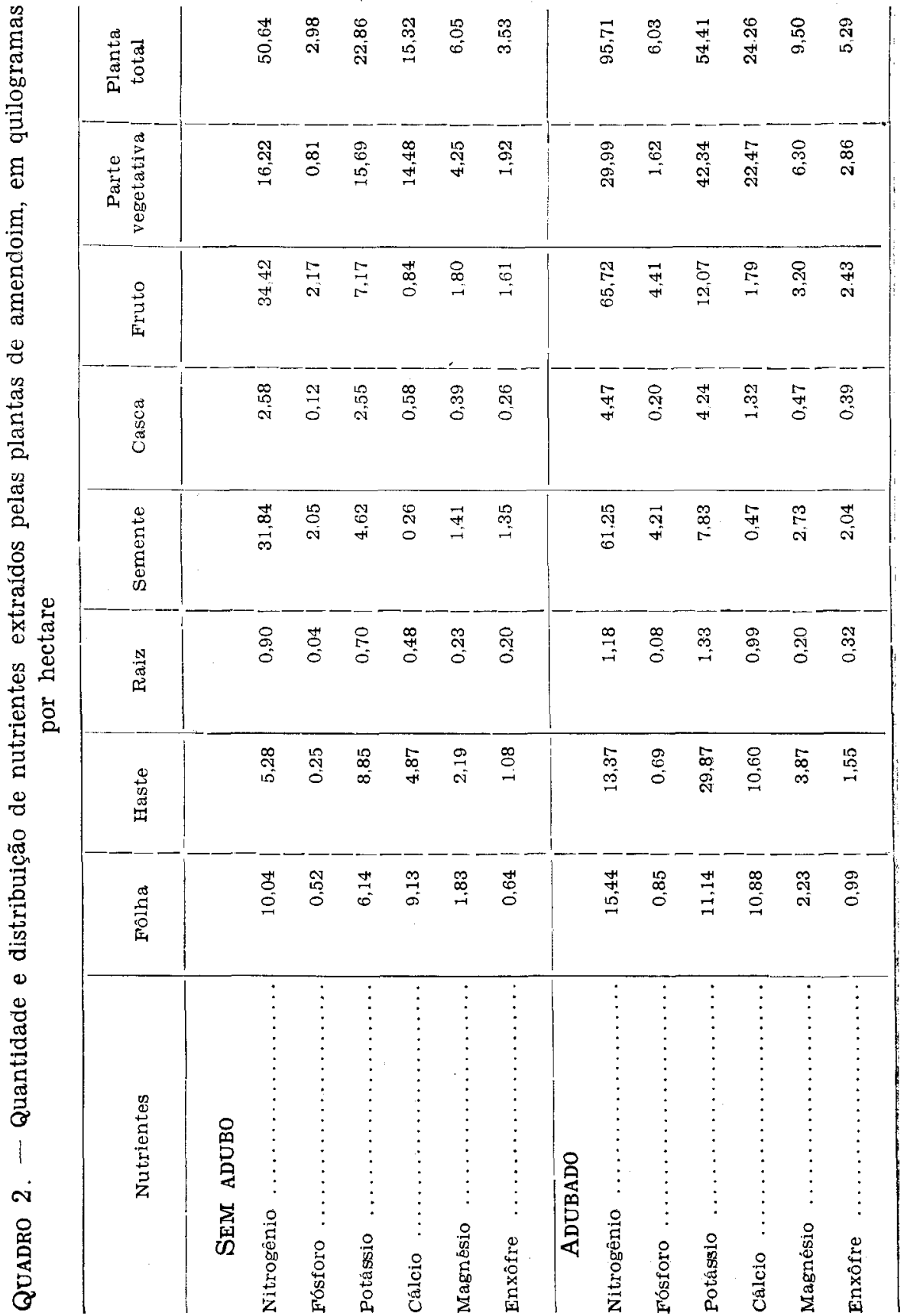


mais ativo de absorção verificou-se entre 49 e 91 dias de idade das plantas, ou seja, do início da frutificação até a época de maturação dos frutos. Naquelas não adubadas a atividade de absorção experimentou um aumento gradativo com a idade das plantas, decrescendo durante a maturação dos frutos.

Na figura 5 são apresentadas as porcentagens do total de
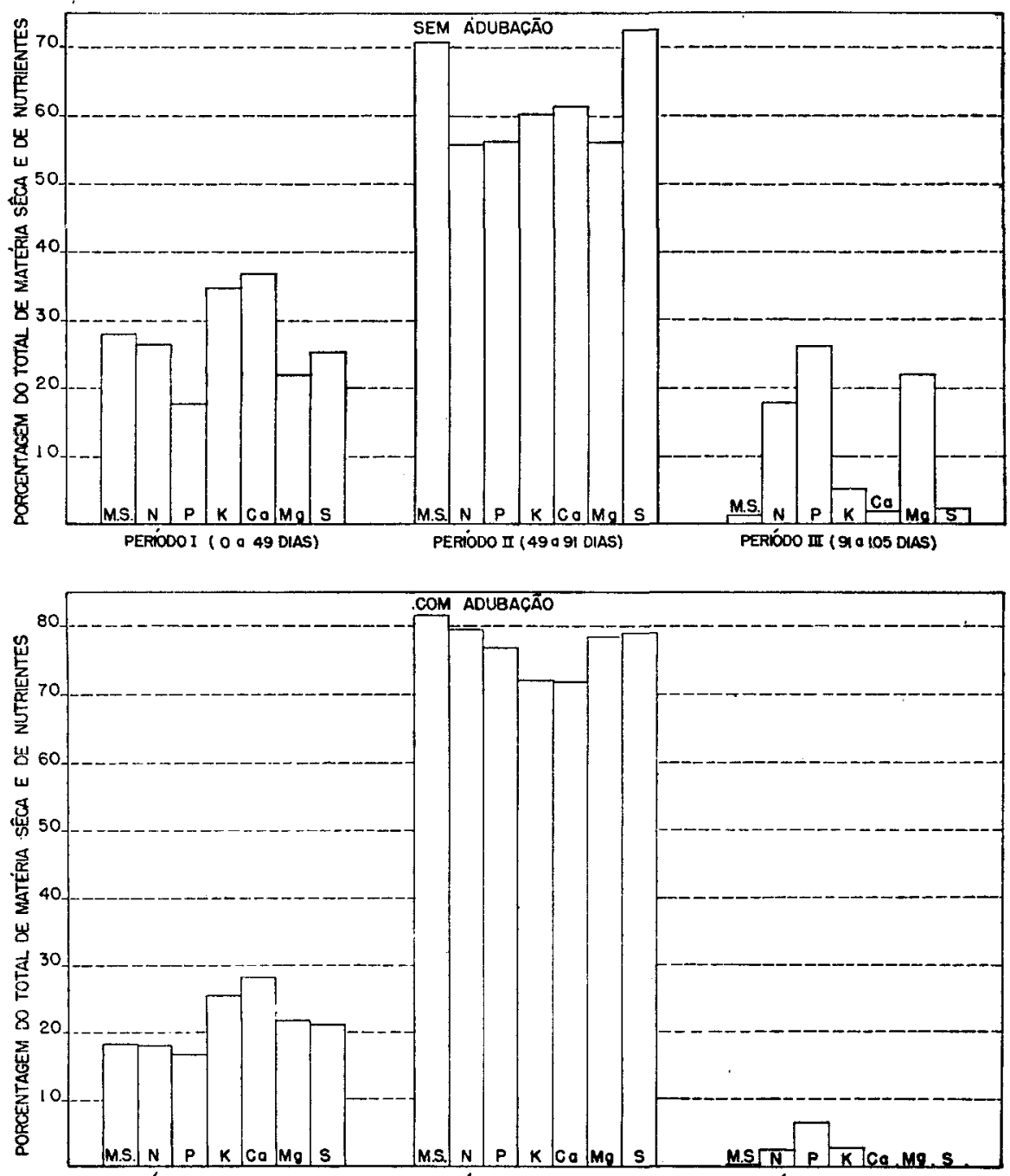
PEṔOOOO I 10049 DAS)

Figura 5. - Porcentagem do total de matéria sêca e de nutrientes acumulados pelas plantas de amendoim, por periodo de desenvolvimento, em solo sem e com adubação. 
matéria sêca e de nutrientes acumulados nas plantas durante o ciclo vegetativo, de acôrclo com o período de intensidade de absorção verificado nas plantas adubadas. Os dados revelam que cêrca de $80 \%$ e $60 \%$ do total de matéria sêca e de nutrientes foram acumulados naquele período de maior atividade de absorção, respectivamente, nas plantas adubadas e não adubadas. Nas plantas adubadas, a partir do final dêsse período, pràticamente não houve acumulação de matéria sêca e de nutrientes.

\section{4 - DISCUSSÃO E CONCLUSÕES}

A acumulação de matéria sêca foi lenta até o início da frutificação, 7 semanas de idade das plantas, tendo alcançado $18 \% \mathrm{e}$ $27 \%$ do pêso sêco máximo atingido pelas plantas durante o ciclo vegetativo, respectivamente, para as plantas adubadas e não adubadas. Nesta fase, que representa o início do "período crítico" das plantas com relaçāo à adubação, esta motivou um aumento de $32 \%$ no pêso total, contra $106 \%$ de aumento, no fim do período crítico, representado pelo início da queda das fôlhas e, fisiològicamente, início de maturação dos frutos.

Durante o "período crítico", houve acumulação de $83 \%$ e $70 \%$ do total de matéria sêca acumulada pelas plantas durante todo o ciclo vegetativo, respectivamente, para as plantas adubadas e sem adubo. Desta data até a colheita, pràticamente não houve acumulação de matéria sêca, processando-se sua redistribuição na planta. À época da colheita, os frutos atingiram um pêso sêco superior ao da parte vegetativa, em ambos os tratamentos, quando se verificou um aumento de $80 \%$ no pêso sêco dos frutos, motivado pela adubação.

A acumulação máxima diária de matéria sêca processou-se entre 70 e 77 dias de idade das plantas.

O "periodo crítico" das plantas com relação à acumulação de matéria sêca, a qual está estritamente ligada à nutrição das plantas, ocorreu bem mais tarde do que na cultura do outono. amendoim da sêca (4), e em estudo de nutrição da cultura realizada com outros países (7), o que deve estar relacionado às condições climáticas, que no nosso caso o clima no outono mostrou-se favorável a um encurtamento no ciclo vegetativo da planta, quando o "período crítico" ocorreu vinte dias mais cedo que na. cultura da primavera. 
De modo geral, a concentração de nutrientes na planta decresceu com a idade dela, com exceção do cálcio e do enxôfre nas plantas não adubadas, os quais tiveram seus teores aumentados com o desenvolvimento das plantas. A raíz apresentou os teores mais baixos em nutrientes, com exceção do enxôfre, cuja concentração foi mais elevada nessa parte da planta. A semente apresentou as concentraçōes mais elevadas em nitrogênio e fósforo e mais baixas em cálcio e magnésio, sendo que nas plantas adubadas o teor de magnésio na raiz foi ligeiramente superio: ao da semente.

As fôlhas e hastes, compreendendo a parte aérea da planta, apresentaram as maiores concentrações em cálcio e magnésio.

Em geral, a adubação motivou aumento na concentração de nutrientes nas partes das plantas, com exceção do cálcio e magnésio; isso se deve ao grande desenvolvimento da parte aérea das plantas, motivado pela adubação, onde se encontra a quase totalidade dêsses elementos, determinando uma "diluição" maior, que poderia também associar-se ao fenômeno antagônico entre potássio, cálcio e magnésio $(12,2,1,5,14)$, segundo o qual, a deficiência de potássio aumenta o teor de cálcio e magnésio, e um excesso provoca uma depressão na absorção dêsses dois elementos.

As oscilações na concentração dos nutrientes nas plantas, principalmente no início do ciclo vegetativo, prende-se ao fato de que os tecidos novos são mais sensíveis às condições climáticas do que os maduros (12).

Alguns autores $(5,10,11)$ têm evidenciado o uso do teor de cálcio na casca como indice de desenvolvimento do fruto, e, também, que as concentrações de nutrientes nas outras partes da planta são pouco afetadas pela adubação. Não se constatou o mesmo no presente trabalho. Não obstante a grande quantidade de cálcio absorvida pelas plantas adubadas, pràticamente não houve diferença no teor de cálcio na casca dos frutos, em ambos os tratamentos.

Nas outras partes da planta, entretanto, notaram-se diferenças apreciáveis nas concentraçōes dos nutrientes, motivadas pela adubação. É o caso do enxôfre (nutriente que afeta o desenvolvimento das raízes e tem importante papel na respiração), que na raíz, orgão que teve o teor mais elevado dêsse elemento, chegou ainda a triplicar-se na planta adubada, em relação à não adubada. 
Com relação à absorção de nutrientes, os resultados evidenciam que a quantidade total de nitrogenio extraido pelas plantas adubadas corresponde a uma e meia vez a quantidade de nitrogênio aplicado como adubo, indicando que nāo foi suficiente para atender às necessidades de restituição.

A semelhança do que ocorre com o nitrogênio, o potássio extraído pelas plantas adubadas corresponde ao fornecido pela adubação.

Harris and Bledsoe (6) relatam sôbre a quantidade apreciável de fósforo nos frutos: a produção e o tamanho da semente são por êle afetados, e acelerada, também, a maturidade e desenvolvimento das raízes. Os dados obtidos indicam que cêrca de $68 \%$ do nitrogênio e $73 \%$ do fósforo extraídos pelas plantas acham-se concentrados nos frutos, mostrando a grande importância dêsses dois elementos nutritivos na obtenção de bons rendimentos culturais.

A parte vegetativa encerra a maior quantidade dos demais nutrientes, sendo que $93 \%$ do cálcio encontra-se nesta parte.

A transmigração de nutrientes na planta foi constatada, notadamente de nitrogênio e fósforo, de tôdas as partes da planta para a semente, uma vez que a acumulação dêstes dois nutrientes diminui na parte vegetativa durante a formação e maturação dos frutos, muito embora a acumulação no fruto e na planta total continui a aumentar, fato também constatado na cultura de outono (4) e por outros autores (13).

O periodo mais ativo de absorção de nutrientes corresponde ao de máxima acumulação de matéria sêca, periodo crítico, e a absorção máxima diária é verificada entre 10 e 11 semanas de idade das plantas. Durante o periodo critico, verificou-se acumulação de cêrca de $89 \%$ e $60 \%$ do total de matéria sêca e de nutrientes acumulados durante todo o ciclo vegetativo, respectivamente, nas plantas adubadas e sem adubação, evidenciando a época em que as plantas devem encontrar maior disponibilidade de nutrientes no solo.

Dentro das condições experimentais em que foi realizado o trabalho, consideramos de maior importância, com relaçāo à nutrição da planta, os seguintes elementos: nitrogênio, potássio, cálcio e fósforo. 
Prevot (13) tem evidenciado a importância do nitrogênio na nutrição do amendoim, sugerindo a manutenção das plantas a um alto nível de metabolismo nitrogenado no periodo anterior à frutificaçāo, principalmente quando as sementes utilizadas no plantio não são inoculadas com microrganismos fixadores dêste nutriente.

Gouny et Prevot, citados em trabalho de nutrição de plantas de amendoim (13), demonstram a grande importância do cálcio sôbre o rendimento do amendoim e que a adição de potássio junto ao cálcio mostrou ser prejudicial. Neste mesmo trabalho, o autor não constatou influência da adubação potássica sôbre a. nutrição cálcica das plantas, o que o levou a supor que em solos deficientes em cálcio, como era o solo em que Gouny et Prevot realizaram o trabalho, êste nutriente atua na mobilização do nitrogênio nas plantas, para formação dos frutos.

\section{NUTRIENT UPTAKE BY PEANUT PLANTS}

\section{SUMMARY}

The dry matter accumulation and absorption as well as the accumulation of nitrogen, phosphorus, potassium, calcium, magnesium and sulfur by peanut in several growth stages under field conditions during the rainy season were investigated.

The experiment was conducted at the Experimental Station "Theodureto de Camargo", in Campinas, where the soil is "dark red latosol". The seed variety used was "Tatu", and treatments comprised plots with

and without fertilizer. The fertilizer treatment included micronutrients. The cultivation and insect and fungi control were those customary in large plantations.

Plant sampling started 15 days after the emergence of the plants, and from then on, once every week, until cropping time. For analytical purposes, the samples were divided into root, stem, leaf, and the fruit. into shell and seed.

The results showed definite patterns of accumulation of nutrients in the plant, as follows: nitrogen and phosphorus in the seed, sulfur in the root and potassium, calcium and magnesium in the stem and foliage. From the supplied elements, nitrogen, potassium and calcium were the most absorbed. 
FERNANDO A. SOARES COELHO \& ROMEU DE TELLA

The highest nutrient demand occurred in the period between early frutification and beginning of leaf shedding, three weeks before the cropping. In this period were accumulated about $80 \%$ and $60 \%$ from the total dry matter and total nutrients, respectively. At cropping time the fruit dry weight was greater than the vegetative part.

\section{LITERATURA CITADA}

1. BONNER, J. \& GALSTON, A. W. Principles of plant physiology. San Francisco, Freeman, 1952. 499p.

2. BURKHART. L. \& COLLINS, E. R. Mineral nutrients in peanut plant growth. Soil Sci. Soc. Amer. Proc. 6:277-280, 1962.

3. \& PAGE, N. R. Mineral nutrient extraction and distribution in the peanut plant. J. Amer. Soc. Agron. 33:743$-755,1941$.

4. COELHO, F. A. S. \& TELLA, R. Absorção de nutrientes por plantas de amendoim na cultura do outono. Campinas, Instituto Agronômico. Bragantia, 26:[235]-252. 1967.

5. COLWELL, W. E., BRADY, N. C. \& PILAND, J. R. Composition of peanut shells of filled and unfilled fruits as affected by fertilizer treatments. J. Amer. Soc. Agron. 37:792-805, 1945.

6. HARRIS, H. C. \& BLEDSOE, R. W. The peanut; the unpredictable legume: a symposium. Washington, Natural Fertilizer Association, 1951. 333p.

7. LACHOVER, D. \& FELDHAY, H. Examem préliminaire de l'absorption de macroélements et du bilan de fertilité du sol chez les Arachides cultivées sous irrigation, en Israel. Oléagineux, 7:599-61.1, 1962.

8. LOTT, W. L. et alii. Levantamento de cafèzais em São Paulo e Paraná pela análise foliar. São Paulo, IBEC Research Institute, 1961. 72p. (Boletim 26)

9. ___ et alii. A técnica de análise foliar aplicada ao cafeeiro. Campinas, Instituto Agronômico, 1956. 29p. (Boletim 79)

10. MEHLICH, A. \& COLWELL, W. E. Absorption of calcium by peanuts from kaolin and bentonite and varying levels of calcium. Soil Sci. 61:369-374, 1946.

11. — REED, S. F. The influence of type of colloid and degree of calcium saturation on fruit characteristics of peanuts. Soil Sci. Soc. Amer. Proc. 4:201-205, 1947. 
12. PETERSON, W. J. \& KRACKENBERGER, H. F. Influence on environment on the chemical composition of plants: a review of the literature. Southern Cooperative Series Bulletin 36, Ithaca, New York, 1954.

13. PREVOT, P. Nutrition minérale le l'arachide. Oléagineux, $4: 69-78,1949$.

14. ROGERS, H. T. Liming for peanut in relation to exchangeable soil calcium and effect on vield, quality and uptake of calcium and potassium. J. Amer. Soc. Agron. 40:15-31, 1948. 